\title{
Seeing the bigger picture
}

\section{British and European science shall each benefit from continued UK membership of the European Union.}

The United Kingdom's 23 June referendum on whether to leave the European Union ('Brexit') presents a serious threat to both British and European science. But it could also provide an opportunity for researchers to reassert the importance and vitality of research collaboration, for both Britain and its European partners.

Until very recently, the referendum campaign has been, in Shakespeare's phrase, "full of sound and fury, signifying nothing." However in late April, the side voting to remain in the EU began to unleash some powerful economic arguments, aided by an unexpectedly forthright intervention by US President Barack Obama.

These rumblings of a serious campaign should now open the way for deeper consideration of the real issues that are at stake. One of these is the centrality of EU membership to UK science policy.

The European Union is an important source of funding for every major university department in the UK, and Britain has been an important political champion for EU research programmes (research is the EU's third largest budgetary activity, after agriculture and so-called structural funds, which support the EU's poorer regions).

Just as significantly, British universities and companies are critical components of the nascent European Research Area - the somewhat abstract but nonetheless vital concept of a genuinely European scientific community, within which people and ideas can circulate freely.

All of this, along with the precursor bodies of the European Union itself, began just after the Second World War, when the United States pushed the European powers to work together at CERN, the European particle physics laboratory near Geneva. It gathered pace with the formation of the European Space Agency (1964) and the European Molecular Biology Laboratory (EMBL; 1974).

As with the EU itself, some British scientists were initially tentative in their commitment to these pan-European endeavours. But they quickly became deeply involved with each of them. Britain also played an important role in the largest panEuropean project of all - the EU Framework Programme, which began modestly in 1984. It is now the largest research programme in the world outside the United States, with a budget of $€ 75$ billion for 2014 to 2020 .

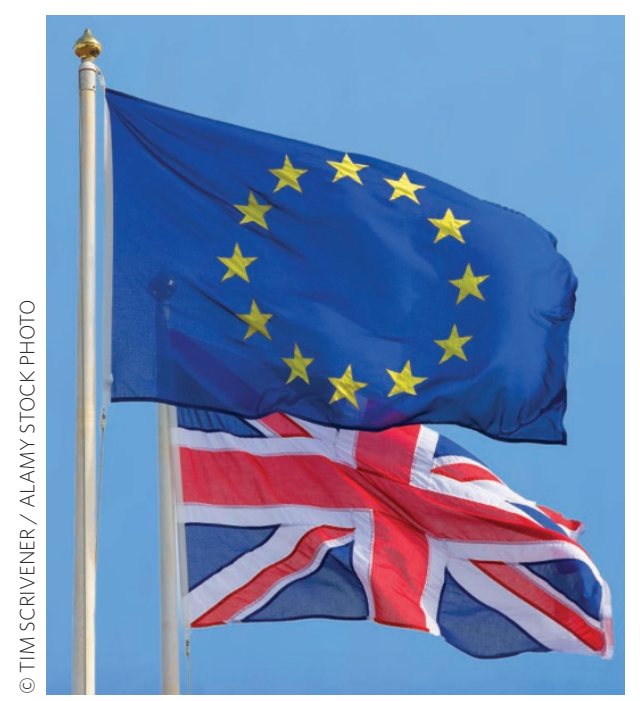

The UK is heavily involved in every part of the latest phase, Horizon 2020, including new, €1-billion flagship initiatives in graphene and possibly in quantum technology. It is the second largest recipient of Framework funds, after Germany, and the largest recipient of grants from the European Research Council (ERC).

Researchers are occasionally blasé about this extraordinary level of cooperation between states that were once bitter rivals. The Brexit referendum provides an opportunity for them to take it for what it really is - a minor, modern miracle.

By way of contrast, try talking to Japanese, Korean and Chinese physicists about the lack of interaction - or even basic communication - between their respective agencies and programmes. Or with South American biologists - or scientists from any discipline anywhere else in the world.

Science in the United Kingdom does not, of course, owe all of its good reputation for international engagement to membership of the European Union. However, most UK scientists would surely agree that they have enjoyed a major transformation in recent years, as EU programmes and EU nationals have assumed a larger presence on UK university campuses.

This transformation doesn't just pertain to research collaboration; the culture of the universities has been changed by an influx of talent, much of it from the rest of the EU.

It is unsurprising, then, that there is little, visible appetite for Brexit at UK universities
(Nature 531, 559; 2016). The cities that host universities teeming with students and staff from abroad — such as London, Edinburgh and Manchester - aren't going to vote for Brexit, and smaller university towns are even less likely to do so.

There's appetite enough for it elsewhere, however, with support for leaving the EU concentrated in older, more homogenous communities. Many there feel that globalization is passing them by, and are quite unaware of the positive impact of the EU on the universities, or on any other aspect of national life.

Along with the Royal Society (http:// go.nature.com/CKkxjW) and most scientific societies, Universities UK (http://go.nature. com/MbwsCN), representing the British university vice-chancellors, has officially announced its support for Britain to remain in the EU. But the vice-chancellors are hardly best placed to influence the general population.

It should be easier for individual researchers, working independently or in concert, to impress on family and friends the extent to which their life and work has benefited from British membership of the EU.

They should also emphasize the extent to which UK participation in the EU generally portrayed in the wider political sphere as grudging or unhelpful - has been an overwhelmingly positive factor in the historical and strategic development of EU research policy.

It may be argued that Britain could continue to participate in Framework and other research collaborations from the sidelines, as Switzerland has done. But Switzerland's role in Horizon 2020 is currently under serious threat after a February 2014 referendum threatened to restrict movement of labour - as Britain would probably try to do if it left the EU.

And Britain is not Switzerland. If it believes itself to be a global scientific power, its job should be to lead European research programmes and projects, not to tag along behind them. This is an unacknowledged role that UK scientists and officials have already often played - in contributing to CERN, managing EMBL and helping to design the ERC, to give just three examples. Following a positive vote for Britain to remain in the EU on 23 June, this role should be strongly reaffirmed. 